\title{
An Investigation on the Connection of English Phonetic Teaching in Primary and Middle Schools in the Context of Curriculum Reform
}

\author{
Wei Zheng ${ }^{1, a}$, Jingjing $\mathrm{Lu}^{2, \mathrm{~b}, *}$ \\ ${ }^{1,2}$ School of Foreign Languages, Zhejiang Ocean University, Zhoushan, Zhejiang 316022 \\ "Corresponding author. Email: lujingjing@zjou.edu.cn
}

\begin{abstract}
Phonetic teaching is one of the important contents of English teaching, and it is the basic level of the whole English teaching. In recent years, English phonetic teaching at the elementary level does not pay attention to students' grasp of phonetic knowledge. After entering junior high school, the teaching content and teaching methods gradually become systematic. Research proves that the current primary and secondary school teachers lack basic teaching communication, failing to provide sound guidance in phonetic teaching in the connection stage, which leads to an unsatisfactory connection of English phonetic learning. This paper intends to study the status quo and the effect of English phonetic teaching in primary and secondary schools in Zhoushan, China. By using the methods of questionnaire, field trip and interview, the author collected the effective data and information in order to offer some rational suggestions on the connection of English phonetics teaching in primary and secondary schools.
\end{abstract}

Keywords: English phonetics teaching, connection

\section{INTRODUCTION}

Since the beginning of the new century, with the country's investment and emphasis in education, the setting time of English courses has gradually extended from the junior high school stage to the elementary school stage in advance and has received increasing attention. Especially after the reform of the new curriculum standards, the quality of teachers and English teaching in primary schools have greatly improved. Nevertheless, under the model of consistent education in primary and junior high schools, solving the problem of teaching convergence has become an imperative task.

This study focuses on the joint influence of the four factors of teachers, students, parents, and society on the connection of phonetic teaching in primary and secondary schools. Due to the differences in English teaching methods, teaching goals, and textbook layout, primary and secondary school English phonetics teaching faces a fault situation. Taking education status of Zhoushan as an example, the above four factors have not been harmoniously integrated into the overall framework and specific stages of English phonetic learning and teaching. Accordingly, in English phonetics teaching, teachers can fully exert the advantages of above four factors so as to combine the wholeness and the stages in a harmonious way.

\section{BACKGROUND}

\subsection{Policy Background}

Educators and scholars in China have conducted a series of investigations and studies on the connection of English phonetic teaching in primary and secondary schools, after the first national "one-stop" conference on basic foreign language education and higher foreign language education held by the Ministry of Education in 1997. It has received all-round attention, and more and more experts and scholars in the field of foreign language teaching have deepened this issue[1].

"Zhejiang Junior High School Academic Proficiency Examination Instructions"(2018) and "The Implementation Opinions of the Zhejiang Provincial Department of Education on Further Promoting the Reform of the School Entrance Examination System in Senior Middle Schools"(2018) put forward the requirements for the gradual development of man-machine dialogue and scientific experimental testing of foreign language listening and speaking skills. In the era of data, English teaching in China pays more attention to the practical use of speaking in English learning. Due to the inadequacy of the assignment and connection of phonetic teaching in primary and secondary schools, students' practical ability cannot adapt to the general trend of curriculum reform. The convergence of teaching is urgent. 


\subsection{Theoretical Background}

American linguist Salinger[2] proposed the Interlanguage Theory in 1972. This theory holds that a second language learner has a specific language system in the learning process. This language system is different from the learner's first language and target language in terms of phonetics, but is a random language. A dynamic language system moves closer to the correct form of the target language as the learning progresses, which expounded the necessity of phonetic teaching. Therefore, English phonetic teaching is one of the important links in English teaching, especially in the country where English is a second language like China. Eric Lenneberg[3], a biologist in America, proposed the Critical Period Hypothesis (CPH) in 1959. He systematically explained the critical period of language learning with "neurophysiology perspective". He believed that the human brain begins to be lateralized at the age of two. Before the lateralization is completed, people use the whole brain to learn language. About age of 11-19, the brain will complete lateralization. From then on, language learning is mainly responsible for the left brain. After the lateralization, language learning is not as good as during the whole brain learning period. Therefore, language learning is best done before the brain has completed lateralization. Chinese students are in this critical period in the transitional period of primary and secondary schools, so it is the golden age and deadline for teaching English phonetics to students. The depth and breadth of the research of English teaching in primary and secondary schools in China is not enough. Fusheng XiaHou[4] put forward in the article "The Problems and Countermeasures of Primary and Secondary School English Teaching Connection" that "English teachers in primary and secondary schools should be familiar with each other's English textbooks and curriculum standards, then design the feasible English teaching scheme with a definite purpose. " The English Curriculum Standard (2011) requires that the primary language teaching for primary school students should recognize the words they have learned and read simple words according to the rules of spelling[5]. It can be concluded that English phonetics teaching plays an important role in English learning in primary schools.

\subsection{The Status Quo of Phonetic Teaching}

On the one hand, there are cognitive differences among primary and secondary school teachers. According to the survey, only $30 \%$ of middle school English teachers believe that it is necessary to conduct a special study on English transitional teaching in primary and secondary schools[6]. (Yuying Bai, 2005) Teachers in primary and secondary schools fail to reach a consensus on the understanding of English teaching connection, which will lead to the lack of a systematic and complete learning process in the transition period between these two stages. On the other hand, there is a lack of transition in teaching methods, content and environment. Through the comparison of the second-level and fifth-level speech standards in the curriculum standards, we find that the two levels have different requirements for students' pronunciation, which needs teachers to explore a suitable connection method in the transition between these two stages to meet the learning needs of students. Nevertheless, the research results of countermeasures in educational connection are rare, so there is still a lot of room for development in the study of connection in English teaching in primary and secondary schools.

\section{RESEARCH DESIGN AND FINDINGS}

\subsection{Research Objects}

This study carried out questionnaire investigation to primary and secondary school students, their parents and front-line teachers from Dinghai No. 2 Middle School and Zhoushan No. 1 Middle School, Zhoushan, China. Among the respondents, most students came from the first grade of junior high school. Since the junior high school teachers can better grasp the students' English proficiency in primary school, the interviewing teachers are all junior high school teachers.

\subsection{Research Methods}

The author sent the questionnaire to the respondents for random sample collection. The content of the questionnaire covers the basic information of the students as well as the condition of mastery of English phonetics. The author also interviewed with front-line teachers, and discussed more effective phonetic teaching models in various aspects. The author held the public welfare classes to summarize and analyze the individual FAQs.

\subsection{Research Results}

According to the data of questionnaire, $45.23 \%$ of the students still don't know much about the new situation of human-computer dialogue under the context of curriculum reform. Although $91 \%$ of the students have learned English phonetics in elementary school, $74.14 \%$ of them did not learn it in elementary school classrooms. $80.00 \%$ of students forget what they have learned after they entered junior high school. $70.41 \%$ of students think that their teachers don't pay much attention to English phonetic teaching. Only $12.50 \%$ of the students have the intention to accept the teaching of phonetic knowledge in the classroom, including $61.42 \%$ of the students believing that the teaching of film music is better. As for the external environment, only $11 \%$ of parents pay attention to the practical use of English and $30 \%$ focus on grade. $23 \%, 12 \%$ and $63 \%$ lay stress on the learning environment, family environment and extracurricular extra-learning respectively to improve the students' English performance. Only 2\% think that social 
the students consistently, cultivating students' ability to use phonetic knowledge independently.

\subsection{In Terms of Parents}

By investigating the current situation of education and analyzing the data obtained in the process of social investigation, the author found that the reason of the disconnection of English phonetic teaching in primary and secondary schools is traceable. As for students, they have misconceptions about English phonetic learning and focus more on English grades than the actual use of English, due to the reality that the "English" textbooks have very little phonetic content and the impact of test-oriented education, even the examination does not involve knowledge of the phonetic part. As for the external environment, teachers are faced with the lack of professional phonetic knowledge training. Parents have blindly enrolled students in informal tuition classes, and there are practical problems such as irrational phonetic knowledge settings in English language teaching materials required by the government. Teachers' accent will make students accept wrong pronunciations, affecting future phonetic learning. Although the method that parents believe to learn in a tuition classes is superficially effective, it doesn't consolidate the English phonetics of most students. As for the textbook (Go for It) for middle school students, it is based on the second level of primary English. However, there is no systematic phonetic teaching in primary school. So, there is a gap in phonetic knowledge, not involving phonetic learning at all.

\section{SUGGESTIONS}

According to the Interlanguage Theory and Critical Period Hypothesis, the author integrates teachers, students, parents, and society to put forward the following suggestions in English phonetic teaching in elementary and middle school stages.

\subsection{In Terms of Teachers}

According to the requirements of the Ministry of Education on the English Curriculum Standard (2011) for middle and primary schools, the junior middle school pays more attention to language communication and use. To adapt to the background of curriculum reform, teachers should change the teaching concept, attach importance to phonetic teaching, grasp the rules of curriculum standards, analyze students' academic situation and carry out innovative activities to optimize English phonetic teaching by "direct spelling" teaching[7]. Through questionnaire surveys and public welfare lessons we see that some students, even after they have learned systematic phonetic knowledge in elementary school, have forgotten the knowledge after entering junior high school due to a long period of nonreview. Therefore, teachers not only need to focus on the teaching of English phonetics, but also need to consolidate
Parents can create a learning environment for their children through audio, fully use the learning software in their mobile phones to assist learning, and choose some scientific and formal counseling institutions for students to get as much exposure to English speech as possible in elementary school. Considering the non-professional nature of parents, parents can use the Internet to input professional knowledge to their children, improving students' English pronunciation through continuous imitation and output.

\subsection{In Terms of Schools}

From the junior high school level, it is necessary to plan the progress of English teaching courses, and intersperse appropriate amounts of English phonetic teaching and practice content. Organize students to take English tests during the enrollment stage, mastering students' English proficiency, and set up English mutual aid groups according to students' ability. The penetration of English phonetics should be achieved in elementary schools. Throughout the primary ascent process, students' speech abilities are uneven. Therefore, it is the most effective way to teach phonetics in elementary school and strengthen it in junior high school, which verifies the correctness of the Critical

\subsection{In Terms of Society}

Firstly, the government needs do a good job of communication and training of primary and secondary school teachers, so that both stages can understand each other's teaching ideas, and achieve the teaching goals and convergence of teaching ideas. Secondly, the society needs to organize various activities inside and outside the classroom to give students enough opportunities to output in English, and to constantly correct and improve their English pronunciation through external professional feedback.

\section{CONCLUSION}

The combination of the four factors required for English phonetic teaching stems from the need to design the teaching process. Because primary schools do not emphasize phonetics well, students are more inclined to memorize mechanically when learning English words and there are also many problems in pronunciation, which has affected English learning in middle schools. The reform of the basic education curriculum is not a product of purely subjective will, but a subjective response of people to the objective needs of a particular socio-political and economic Period Hypothesis. 
development. In the current context of increasingly frequent exchanges among countries, comprehensive talents with fluent English and pure accents are needed in English education in our country, rather "Dumb English" under testoriented education. Because of this need, man-machine dialogue has become part of the Zhejiang middle school entrance examination project, which shows that the current English education attaches great importance to English phonetic teaching.

In addition, English phonetic teaching is a kind of basic teaching, which is easily affected by the learning environment. Although more and more parents are beginning to pay attention to the practical use of English, some parents still ignore their children's English phonetic learning. For this reason, it is necessary to integrate parents into the influencing factors of English phonetics learning, to promote parents to form a correct consciousness, and to assist teachers in English phonetics teaching according to the actual situation.

All in all, with the continuous reform of teaching materials, enabling students to lay a phonetic foundation in elementary school will become one of the directions for future English curriculum reform. At the same time, combining teachers, schools, parents and society as a community is undoubtedly suitable for China's national conditions of learning English phonetics.

\section{REFERENCES}

[1]. T. R. Bao. Interview with Principal Dai Weidong[J]. Foreign Language Teaching\& Research in Basic Education, 2008, 7-12.

[2]. Selinker, L. Interlanguage[M]. Edinburgh University Press. 1972.

[3]. Lenneberg, E. Biological Foundation of Language[M]. New York: Wiley, 1967,17-39.

[4]. F. S. Xiahou. Issues and Solutions to English Teaching in Elementary and Middle Schools[J]. Foreign Language Teaching\& Research in Basic Education, 2003, 12-15.

[5]. Ministry of Education of the People's Republic of China[C]. English Course Standard. Beijing Normal University Press, 2001.

[6]. Y. Y. Bai. A Discussion on How English Teachers of Junior Middle School Cope with the Problem of English Cohesion[J]. Primary and Middle School Teaching Research, 2005,8.

[7]. S. Zhuo. Effective Implementation of Straight Spell Teaching in English Teaching in Primary Schools[J]. Primary school instructional design, 2007, 12-14. 